Res Pública Revista de Historia de las Ideas Políticas

ISSN: 1131-558X

https://dx.doi.org/10.5209/rpub.70315

\title{
El vacío del populismo latinoamericano frente a la ontología política europea ${ }^{1}$
}

\author{
Adrià Porta Caballé*
}

Recibido: 25 de junio de 2020 / Aceptado: 8 de septiembre de 2020

Resumen. El presente artículo pretende mirar a Latinoamérica desde la perspectiva de la ontología. Y como hay algo que no acaba de encajar, busca en el inexplorado terreno de la meontología y el no-ser a partir de dos pensadores políticos latinoamericanos recientes, Dussel y Laclau. Por un lado, la Filosofía de la Liberación asocia el centro con la ontología y el ser, así como la periferia con lo Otro y el no-ser. De esto se desprende que, aun y asumiendo el heideggeriano "olvido del ser", la ontología helenocéntrica se basa en la negación aún más originaria y fundamental de la nada. A continuación, se intenta demostrar cómo esta renegación ha ido de la mano de la exclusión de lo bárbaro, lo popular y lo femenino, principalmente. Tras un breve ex cursus sobre Schmitt en tanto que la forma más acabada de horror vacui dentro de la ontología política europea, el artículo concluye con un análisis pormenorizado de la reconceptualización del vacío en la obra de Laclau, que puede permitir una mejor comprensión del populismo en general, y de su vertiente latinoamericana en particular.

Palabras clave: vacío; ontología política; Latinoamérica; Dussel; Schmitt; Laclau.

\section{[en] The Emptiness of Latin American Populism against European Political Ontology}

\begin{abstract}
The present article pretends to look at Latin America from the perspective of ontology. And since there is something that does not quite fit, it searches in the much unexplored terrain of meontology and non-being in two recent Latin American political thinkers, Dussel and Laclau. On the one hand, the Philosophy of Liberation associates the center with ontology and being, as well as the periphery with the Other and non-being. It follows from that, that even assuming the Heideggerian "forgetfulness of being", Hellenocentric ontology is based on the even more originary and fundamental negation of nothingness. Next, an attempt is made to demonstrate how this repudiation has gone hand in hand with the exclusion of the barbaric, the popular and the feminine. After a brief ex cursus on Schmitt as the most complete form of horror vacui within European political ontology, this article concludes with a detailed analysis of the reconceptualization of emptiness in Laclau's work, which may allow a better understanding of populism in general, and its Latin American form in particular.
\end{abstract}

Keywords: Emptiness; Political Ontology; Latin America; Dussel; Schmitt; Laclau.

Sumario. 1. El "olvido del ser" y la renegación del no-ser. 2. El ser del centro y el no-ser de la periferia. 3. El horror vacui de la ontología política europea. 4. El vacío del populismo latinoamericano. Bibliografía.

Cómo citar: Porta Caballé, A. (2021). El vacío del populismo latinoamericano frente a la ontología política europea. Res Pública. Revista de Historia de las Ideas Políticas, 24(1), 63-74.

De Parménides a Heidegger, los filósofos han escrito un drama de un solo acto cuyo héroe se llama Ser

Simon Critchley ${ }^{2}$

\footnotetext{
Universidad de Barcelona

adriaportac@gmail.com

El presente artículo es el resultado del II Seminario Internacional "Latinoamérica en perspectiva", que tuvo lugar en la Universidad de Harvard los días 22-23 de mayo de 2019. En particular, pretende mirar a Latinoamérica desde la perspectiva de la ontología y, como hay algo que no acaba de encajar, busca en el inexplorado terreno de la meontología y el no-ser. Así, este ensayo no representa tanto la presentación ofrecida en ese seminario, como una posterior problematización, ampliación y desarrollo a partir de las preguntas que le siguieron, por parte de Jorge Álvarez Yagüez o Jacques Lezra, por ejemplo, y a las que debo mi más sincero agradecimiento. En especial, está escrito como una respuesta a las dos interesantes preguntas críticas de José Luís Villacañas sobre la ontología política de Schmitt y la teología negativa de Laclau. Este artículo también se puede leer como la segunda parte de: A. Porta Caballé, "El vacío de Podemos: meontología política del cambio en España”, Escrituras americanas, 2020, en publicación. Todas las traducciones de títulos en lengua extranjera son mías.

2 S. Critchley, The Problem with Levinas, Oxford, Oxford University Press, 2015, p. 105.
} 


\section{El "olvido del ser" y la renegación del no-ser}

Toda la historia de la filosofía occidental ha sido la historia del ser. Incluso Heidegger, para quien esta no representa más que el progresivo "olvido del ser", reconoce el doble sentido del genitivo: el pensamiento (occidental) pertenece al ser y a la vez está a la escucha del ser ${ }^{3}$. En esta medida, recuerda el ser incluso cuando lo olvida, o lo recuerda en su olvidar. Mutatis mutandis, esta es la misma lógica que Freud aplica a la negación (Verneninung): algo tiene que ser registrado hasta cierto punto y de alguna manera para ser repudiado. “«Usted pregunta quién puede ser la persona del sueño. Mi madre no es». Nosotros rectificamos: Entonces es su madre. Nos tomamos la libertad, para interpretar, de prescindir de la negación y extraer el contenido puro de la ocurrencia"4. Dicho esto, Lacan distingue entre tres tipos de negación (Verneinung) $)^{5}$ :

\begin{tabular}{|l|l|l|}
\hline Categoría & Negación & Verneinung \\
\hline Neurosis & Represión & Verdrängung \\
\hline Perversión & Renegación & Verleugnung \\
\hline Psicosis & Forclusión & Verwerfung \\
\hline
\end{tabular}

La pregunta es: ¿dónde encaja aquí el llamado "olvido del ser'? Y la respuesta es que en la represión (Verdrängung), propia de la neurosis, pues Freud la define como el "padecimiento de reminiscencias"6. Desde que Andrónico de Rodas organizó los libros "más allá" ( $\tau$ ò

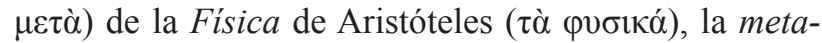
física se ha referido a la ciencia que estudia el "ser en tanto que ser"'. Y a pesar de que para Heidegger esta pregunta dejó de ser planteada de forma explícita y temática, no se puede negar que la metafísica ha intentado recurrentemente encontrar la determinación del ente en su totalidad: sea el cĩ $\delta$ oc (forma) en Platón, la causa sui (Dios) en Santo Tomás de Aquino, la res cogitans (cosa pensante) en Descartes, der Geist (el espíritu) en Hegel, o der Wille zur Macht (la voluntad de poder) en Nietzsche. La deconstrucción, al igual que el marxismo o el psicoanálisis, es inferencial: deriva patologías de síntomas. Y así, el hecho de que la metafísica trate siempre de todo lo ente ( $\tau \alpha$ ò $v \tau \alpha$ ) sin preguntar a su vez ¿qué es el ser? ( $\tau \tilde{\omega}$ o้v) se puede percibir solo en sus efectos. Ahora bien, si el ser representa el caso de la represión (Verdrängung) en la historia de la filosofía occidental, ¿en qué categoría encajaría la nada? Es mi tesis en este artículo que ella representa una negación (Verneinung) aún más fundamental y originaria.

M. Heidegger, Carta sobre el humanismo, Madrid, Alianza, 2006, p. 15.

$4 \quad$ S. Freud, "La negación”, Obras completas (Vol. XIX): El yo y el ello $y$ otros ensayos de metapsicología, Buenos Aires, Amorrortu, 2000, p. 253.

5 J. Lacan, Le Séminaire (Vol. III): Les psychoses, Paris, Seuil, 2018. Cf. también: B. Fink, A Clinical Introduction to Lacanian Psychoanalysis: Theory and Technique, Cambridge, Harvard University Press, 1997 p. 76.

6 S. Freud, Obras completas (Vol. II): Estudios sobre la histeria, Buenos Aires, Amorrortu, 2000, p. 33.

Aristóteles, Metafisica, Madrid, Alianza, 2008, Г.1003a, p. 110.
La filosofía, como ontología, no nace con Sócrates: este no representa más que el referente ético, trágico y casi mesiánico de un "camino de la verdad" $(\alpha \lambda \eta \dot{\theta} \theta \varepsilon 1 \alpha)$ descubierto mucho antes en Elea. Leído como el negativo de una fotografía, el poema de Parménides Acerca de la naturaleza no significa tanto una reflexión sobre el ser como una prohibición sobre el no-ser: "el otro [camino], el de que no es y el de que es preciso que no sea, / éste te aseguro que es sendero totalmente inescrutable. / Y es que no podrías conocer lo que no es -no es alcanzable- / ni tomarlo en consideración" ". Es más: "es que nunca se violará tal cosa, de forma que algo, sin ser, sea. / Así que tú aparta de esta vía de indagación tu pensamiento". Resumiendo, tenemos que el camino del no-ser "es": inescrutable, incognoscible e inalcanzable. La eterna pregunta hermenéutica sobre por qué Parménides recomienda apartarse de un camino que a su vez es "impensable"10 se clarifica desde la perspectiva de la renegación fetichista (Verleugnung), donde el fetiche es encumbrado como un objeto a la vez necesario e imposible. La aparente contradicción entre el (no-)ser y el (no) deber ser de esta falacia naturalista invertida desaparece cuando asumimos, con la ayuda del psicoanálisis, la "oscilante estructura del fetiche"11 que produce un "simultáneo registro y repudio" 12 . Por tanto, en el pico originario del pensamiento explícito y temático sobre el ser, con Parménides, aquello que es negado bajo la forma de una renegación fetichista (Verleugnung) es el no-ser.

En realidad, los filósofos presocráticos discutieron dos conceptos me-ontológicos que se hace imperioso distinguir analíticamente desde el principio, aunque estén íntimamente ligados: el no-ser ( $\tau \tilde{\omega} \mu$ í őv, de donde

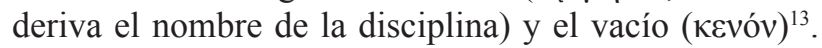
En ningún caso se puede ver esta diferencia de forma tan acuciante como en los atomistas, que podrían haber supuesto "otro comienzo" en la historia de la metafísica distinto del eleático, quizás más materialista y permisivo con el vacío. En efecto, Demócrito y Leucipo están de acuerdo con Parménides en que el vacío no es - no "participa" del ser-, y tampoco puede ser generado (ex nihilo nihil fit); sin embargo, tiene que ser asumido como

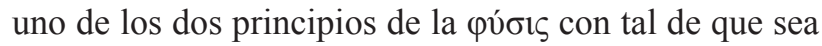
posible el movimiento (contra el argumento de Meliso de Samos). Como dicen, "por convención, el color; por convención, lo dulce; por convención, lo amargo: pero en realidad átomos y vacío"14. Sin embargo, Aristóteles, en el libro cuarto de la Física (que, recordemos, para Heidegger es la obra meta-física más influyente de Occidente), establecerá el principio milenario de que la naturaleza aborrece el vacío (horror vacui $)^{15}$. Y no será hasta

8 A. Bernabé (ed.), "Parménides de Elea", Fragmentos presocráticos: de Tales a Demócrito, Madrid, Alianza, 2008, fr. 2, p. 156.

Ibidem, fr. 7, p. 157.

$10 \quad$ Ibidem, fr. 3, p. 156.

11 A. Bass, Difference and Disavowal: The Trauma of Eros, Stanford, Stanford University Press, 2000, p. viii.

12 A. Bass, Fetishism, Psychoanalysis and Philosophy: the Iridescent Thing, Nueva York, Routledge, 2018, p. 1.

13 Para una magnífica historia de este concepto: A. Ribas, Biografia del vacio, Barcelona, Sunya, 2008

14 A. Bernabé (ed.), "Los primeros atomistas", op. cit., fr. 125, p. 295.

15 Aristóteles, Física, Madrid, Gredos, 1995, IV.B.6-9 213a12-217b27, pp. 132-147. 
el s. XVII, y no sin grandes dificultades, que el discípulo de Galileo, Torricelli, demuestre su existencia al meter un tubo en una cubeta de mercurio ${ }^{16}$.

Ahora bien, a pesar de este horror milenario impuesto por Aristóteles, podría parecer que el pensamiento físico y metafísico occidental ejecutó sobre la nada una exclusión aún más radical que la renegación (Verleugnung) de Parménides. Estamos hablando de la forclusión (Verwerfung). Para Lacan, robando del lenguaje jurídico, lo que caracteriza a este mecanismo es que lo excluido ni está ni se le espera; ni tan siquiera está olvidado, reprimido, o denegado en el pensamiento: simplemente no está. Y esta bien podría ser la tipología más frecuente que ha sufrido el no-ser en la historia de la metafísica occidental, desde Elea hasta Freiburg -para reformular la expresión de Rosenzweig. La forclusión podría explicar las enormes lagunas que ha sufrido la preocupación por el vacío, saltando del atomismo a la me-ontología neo-platónica, y de la teología negativa a la ciencia moderna, hasta llegar por fin al existencialismo. Por no hablar de los "brotes psicóticos" por parte de la lógica, la matemática y la escolástica (todas asentadas en una ontología helenocéntrica) cada vez que este tema se ha planteado nuevamente. Sin embargo, esta tentación de caer en la más radical de las negaciones topa con un contrargumento definitivo: incluso lo más denegado requiere de alguna forma, aunque tenue e inconsciente, un simultáneo registro de aquello que se niega. Por tanto, la primera tesis de este ensayo reza: incluso asumiendo el heideggeriano "olvido del ser", la filosofía occidental se asienta sobre una exclusión aún más fundamental y originaria, la renegación de la nada.

\section{EI ser del centro y el no-ser de la periferia}

El centro es, la periferia no-es.

\section{Enrique Dussel ${ }^{17}$}

Enrique Dussel empieza su Filosofía de la Liberación, de inspiración levinasiana, asociando el centro con la ontología y el ser, así como la periferia con lo Otro y el noser. Esta segunda vinculación ya es en sí misma original y novedosa, pues no se encuentra en Levinas. El discípulo crítico de Heidegger se halla en este punto de acuerdo con su maestro. Efectivamente, Heidegger es uno de los pocos filósofos occidentales que ha tratado el problema de la nada, pero desde ¿Qué es la metafísica? lo sitúa en el lado del ser en la diferencia ontológica con el ente ${ }^{18}$. La formulación más acabada de este pensamiento dice "Ser: Nada: Mismo" (Sein: Nichts: Selbst) ${ }^{19}$. Con esta expresión, Heidegger pretende heredar y a la vez separarse del comienzo de la Ciencia de la Lógica de Hegel:

F. Close, The Void, Oxford, Oxford University Press, 2008, pp. 14 ss. 7 E. Dussel, Filosofia de la Liberación, México, Fondo de Cultura Económica, 2018, p. 27.

18 M. Heidegger, ¿Qué es metafísica?, Madrid, Alianza, 2009, p. 29.

19 M. Heidegger, Four Seminars, Bloomington, Indiana University Press, 2003, p. 58. "el puro ser y la pura nada es lo mismo"20 -ya que el problema no es que sean lo "inmediato indeterminado" sino justamente la "metafísica de la presencia" que así los caracteriza. Levinas no encuentra tanto un problema en esta intuición heraclítea compartida por ambos filósofos alemanes, como con el tercer término "lo mismo" (Selbst). Y aunque en su seno se encuentre mediado por "negaciones determinadas" o "diferencias", este hecho no quita la subsunción dentro del Uno mismo ( $\alpha$ ứç) del que Levinas precisamente quiere escapar con el Otro

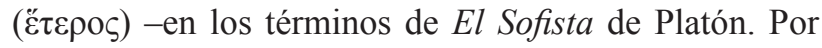
esta razón, en incontables ocasiones que resulta imposible citar aquí de forma exhaustiva, Levinas considera la nada como el mero reverso del ser dentro de la ontología. Para poner tan sólo tres ejemplos de su clásico De otro modo que ser, Levinas se refiere al "más allá de la esencia" como el "más allá del ser y del no-ser", "un olvido del ser y del no-ser", "una diferencia respecto de la cópula ser y no-ser"'21, etcétera, etcétera. Por contra, es el mérito de Dussel haber vuelto a poner la nada y lo Otro, juntos. También él se remonta a Elea a la hora de identificar el origen del problema: "el otro es alteridad de todo sistema posible, más allá de «lo mismo» que la totalidad siempre es. El ser es y el no-ser es todavía o puede serlo el otro, diríamos contra Parménides y la ontología clásica"'22. Entre bastidores, como no podría ser de otra manera, se encuentra el "parricidio" perpetrado por el extranjero eleata contra Parménides en El Sofista de Platón, cuando finalmente obliga: "a lo que no es, a que sea en cierto modo, y recíprocamente, a lo que es, a que de cierto modo no sea" 23 .

No hace falta ir tan lejos. En este artículo no ambicionamos resolver de manera definitiva el problema filosófico del no-ser, de si "es" en "cierto modo", hasta qué punto, o qué cosa "sería" (si es que una empresa tal es tan siquiera posible, ya que por lo pronto infringe el principio aristotélico de no-contradicción y levantaría una sonrisa en un positivista lógico como Carnap ${ }^{24}$ ). Simplemente pretendemos preguntar qué le ha pasado históricamente al no-ser, y desentrañar sus asociaciones metafóricas con determinados lugares y sujetos. Ya sabemos que ha sufrido una renegación tan fundamental como originaria. Lo siguiente será reconocer, con la ayuda de Dussel, que esta queda lejos de ser "neutral" políticamente.

La filosofía egipcia se desarrolla en sus colonias (Atenas lo fue de Sais, ciudad del Delta del Nilo). Parménides, desde la periferia de la Magna Grecia, enunció el comienzo radical de la filosofía como ontología: "El ser es, el no-ser no es". ¿Qué es el ser sino el fundamento del mundo, el horizonte que comprende la totalidad dentro del cual todo cobra sentido, la frontera del mercado que controlan los ejércitos? El ser coincide con el mundo, es como la luz (tò

\footnotetext{
G. W. F. Hegel, Ciencia de la lógica, Madrid, Abada, 2011, p. 226.

21 E. Levinas, Autrement qu'être, ou au-délà de l'essence, Paris, Livre de Poche, 2004, pp. 77, 272, 22.

22 E. Dussel, op. cit., p. 60.

23 Platón, "Sofista", Diálogos V, Madrid, Gredos, 1988, 241d, p. 401.

24 R. Carnap, "The Elimination of Metaphysics through Logical Analysis of Language", A. J. Ayer (ed.). Logical Positivism, Nueva York, The Free Press, 1959, pp. 60-81.
} 
fôs) que ilumina un ámbito y que no es vista. El ser no se ve; se ve lo que él ilumina: las cosas (tà ónta), la palabra (el lógos), los útiles (tà prágmata). El ser es lo griego, la luz de la propia cultura griega. El ser llega hasta las fronteras de la helenicidad. Más allá, más allá del horizonte, está el no-ser, el bárbaro: Europa y Asia. Es en la política, la de Platón, Aristóteles, Epicuro, de los estoicos, donde se descubre el sentido de la ontología ${ }^{25}$.

Lo más interesante para nosotros de este pasaje de Dussel es la asociación que desentraña entre el no-ser y lo bárbaro. En efecto, la pretensión que surge desde Jonia en el s. VI de explicar todo "lo que es" ( $\tau \grave{\alpha}$ ő $v \tau \alpha$ ) desde "su ser" ( $\tau \tilde{\omega}$ ǒ $v)$ presupone una determinada concepción de la totalidad ( $\alpha$ $\tau$ ós, Selbst), y por lo tanto

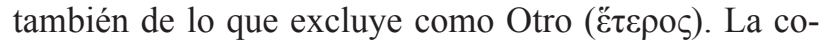
rrespondencia entre esta alteridad y lo bárbaro no es arbitraria, sino que se puede y se debe rastrear ya en el poema de Parménides.

Mas también de esta otra [vía], por la que de cierto mortales que nada saben,

andan errantes, como con dos cabezas, pues la incapacidad que anida

en sus pechos torna derecho un pensamiento descarriado. Y ellos se ven arrastrados

sordos y ciegos a un tiempo, estupefactos, horda sin discernimiento,

a quienes de ordinario ser y no ser les parece lo mismo

y no lo mismo, y de todas las cosas es regresivo el camino ${ }^{26}$.

En realidad, en el poema de Parménides no hay tan solo dos caminos, el del ser y el del no-ser, sino tres. De acuerdo con Heidegger, el tercer camino es el de "la $\delta$ ó $\xi \alpha$ en el sentido de la apariencia"27, en especial oposición al de la verdad como des-cubrimiento $(\alpha \lambda \hat{n} \theta \varepsilon i \alpha)$. Por el primero "andan errantes" "mortales que nada saben", "sordos y ciegos", "como con dos cabezas" y con un "pensamiento descarriado". No parece un camino muy halagüeño, ciertamente, y por esto hemos dicho antes que Sócrates solo representa el referente ético, práctico y casi mesiánico de un "camino de la verdad" descubierto mucho antes en Elea: pues aquí ya se encuentra el cisma entre $\alpha \lambda \eta \dot{\theta} \theta \varepsilon \iota \alpha$ y $\delta$ ó $\xi \alpha$ que acarrearía consecuencias tan trágicas en Atenas. Por otra parte, los manuales de filosofía interpretan demasiadas veces este pasaje como una "polémica entre filósofos", en particular contra Heráclito, cuando hay que leer de manera literal la referencia a una "horda sin discernimiento". Así es como Bernabé traduce, correctamente, el término griego $\varphi \tilde{u} \lambda o v$, ya que captura su doble sentido ambiguo. En un diccionario griego podemos leer la definición: "raza, linaje, estirpe, tribu, pueblo; género, especie; conjunto numeroso de individuos o seres de la misma especie, muchedumbre"28. Entonces, esta "tribu" que se guía por las apariencias y las opiniones y, más fundamentalmente, que es incapaz de "discernir" entre el ser y el no-ser:

E. Dussel, op. cit., p. 26.

A. Bernabé (ed.), op. cit., fr. 6, p. 157.

27 M. Heidegger, Introducción a la metafísica, Barcelona, Gedisa, 2003, p. 106.

28 J. M. Pabon, Diccionario manual griego. Griego clásico-español, Madrid, Vox, 2007, p. 633. ¿se refiere a lo bárbaro o a lo popular, es una raza o una muchedumbre? Aquí hay una ambigüedad, productiva en el poema, que no es nada más que el reverso de otra. El concepto oủoí $\alpha$, encumbrado por Platón y Aristóteles como el "ser", la "esencia" o la "sustancia" de las cosas, significa también "fortuna, hacienda, bienes, riqueza"29 (esta ambivalencia se mantiene en el español hasta día de hoy pasando por la traducción latina de substantia). Por tanto, es mi segunda tesis en este ensayo que el privilegio del ser está asociado a la riqueza (abundancia de entes), mientras que el del no-ser queda excluido junto al pueblo y lo bárbaro. Sin embargo, la "cadena de equivalencias" no se detiene aquí, ni mucho menos:

El mejor diagnóstico europeo del machismo lo ha propuesto Freud. Vio claramente que "la sexualidad es por naturaleza (cultural) masculina", y por ello el falo fue definido como constituyente y activo, y la vagina como pasiva y constituida: objeto sexual. "El ser es, el no-ser no es", en ontología erótica debe enunciarse: "El falo es, la castración no es". Es decir, la mujer no es; es sólo objeto, como lo era en la política el indio, el africano, el asiático, las naciones pobres, las clases oprimidas, el pobre ${ }^{30}$.

En efecto, no solo lo bárbaro y lo popular quedan asociados con el no-ser, también lo femenino. Y como apunta Dussel, el psicoanálisis freudiano representa la mejor explicación, así como el caso más paradigmático, de este hecho. Como reconoce Bass, "para Freud la cuestión de la nada es de manera crucial la cuestión de la castración" 31 . Y el salto de la una a la otra se puede resumir en tres argumentos bajo la forma de un silogismo. Primero, Freud describe los genitales femeninos como una suerte de vacío. Es curioso que el pensador que escribiera Die Traumdeutung justamente para desbancar la interpretación "simbolista" de los sueños, se permitiera un breve diccionario "descifrador" de esta índole: "todos los objetos alargados, bastones, troncos de árbol, paraguas, quieren ser los subrogados del miembro masculino, como también todas las armas largas y puntudas: cuchillos, puñales, picas. (...) Los estuches, cajitas, cofres, armarios, hornos, corresponden al vientre femenino, como también cavidades, barcos y toda clase de recipientes" 32 . En segundo lugar, Freud concibe el receptáculo vacío de los genitales femeninos como una ausencia: "«ahí falta algo» describe el carácter principal de los genitales femeninos"33. Más aún, la supuesta "castración" de las mujeres es un Faktum, un "hecho biológico". Por lo tanto, si los genitales femeninos representan una especie de vacío, y este vacío es concebido como una ausencia (del falo), las mujeres tendrían "envidia del pene". QED.

Ahora bien, este silogismo falogocéntrico de Freud hace aguas por los tres costados. Para empezar, ¿por qué elegir los genitales como punto de referencia de la "di-

Ibidem, p. 440 .

E. Dussel, op. cit., p. 97.

31 A. Bass, "Fetishism, Reality, and «The Snow Man»", American Imago, 48(3), p. 308.

32 S. Freud, Obras completas (Vol. V): La interpretación de los sueños (segunda parte), Buenos Aires, Amorrortu, 1991, pp. 359-60.

33 S. Freud, Obras completas (Vol. IV): La interpretación de los sueños (primera parte), Buenos Aires, Amorrortu, 1991, p. 337. 
ferencia anatómica"? Por un lado, incluso el genitalismo de Freud tantea la idea de que el clítoris pueda ser considerado como "un auténtico sustituto del pene"34 [sic]. Por el otro, si se toman los pechos de la madre como ejemplo, toda la dicotomía presencia/ausencia se viene abajo. Además, ¿por qué entender un supuesto vacío como la ausencia (del falo)? Es aquí donde entran en juego todos los prejuicios de la ontología de Parménides en adelante. Quizás la principal conclusión que podemos extraer de todo esto es la íntima relación entre la diferencia ontológica y la diferencia sexual que ya Irigaray anunció ${ }^{35}$. Las dicotomías ser/no-ser, presencia/ ausencia, falo/castración están tan profundamente imbricadas hasta el punto de que el plenismo ontológico representa un falogocentrismo. Quizás este pudiera ser el significado del misterioso y aislado fragmento 17 de Parménides: "a derecha, niños; a izquierda, niñas"36. En cualquier caso, la mejor crítica a esta ontología falogocéntrica de Freud ha sido llevada a cabo, otra vez, por Irigaray:

su sexo representa el horror del nada que ver. Es un defecto en este sistema de representación y deseo. Un "agujero" en su objetivo escoptofílico. Que este nada que ver, debe ser excluido, rechazado, de tal escena de la re-presentación ya se puede ver en la estatuaria griega. El sexo de la mujer simplemente está ausente: oculto, cosido en su "corte" ${ }^{37}$.

De nuevo topamos con el horror del "nada que ver" ligado con la cosmovisión griega. En este momento también estamos mejor equipados para reconocer porqué hemos caracterizado semejante horror vacui como una renegación (Verluegnung). Como dice Irigaray, un tal "agujero" tiene que ser "excluido, rechazado". Si seguimos su lectura de la $\chi \omega ́ \rho \alpha$ en el Timeo, también encontraremos que "lo femenino" es aquello que queda justamente fuera de toda ontología, un receptáculo vacio "más allá" incluso de la diferencia sexual (patriarcal) hombre/mujer representada por Platón como el

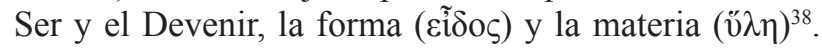
También para Kristeva el "cuerpo materno" representa una experiencia semiótica que raya la "psicosis"39-cuyo mecanismo, recordemos, es la forclusión. Por último, Butler criticará en ambas pensadoras su tratamiento de la homosexualidad, pues si vemos la penetración (o su falta) como lo fundamental en la lectura de la $\chi \omega ́ \rho \alpha$, esta tiene que incluir necesariamente también lo que queda fuera de la matriz heterosexual ${ }^{40}$. En cualquier caso, el receptáculo vacío de la $\chi \omega ́ \rho \alpha$ se convierte en el término dentro del pensamiento griego que representa todo lo que queda re-negado de la ontología griega. Ahora,

34 S. Freud, Obras completas (Vol. VII): Tres ensayos de teoría sexual y otras obras, Buenos Aires, Amorrortu, 1992, p. 178.

35 L. Irigaray, Éthique de la différence sexuelle, Paris, Minuit, 1984, p. 13.

36 A. Bernabé (ed.), op. cit., fr. 17, p. 161.

37 L. Irigaray, "Ce sexe qui n'est pas un", Les Cahiers du GRIF, 5, 1975 , p. 55.

38 L. Irigaray, Speculum de l'autre femme, Paris, Minuit, 1974.

39 J. Kristeva, Polylogue, Paris, Seuil, 1977, pp. 409-35.

40 J. Butler, Gender Trouble, Nueva York, Routledge, 2006, pp. 107127; J. Butler, Bodies That Matter, Nueva York, Routledge, 2011, pp. 11-27. habiendo terminado este breve ex cursus sobre el sexo, el género y la sexualidad en particular, y sobre la cadena de equivalencias del no-ser en general (que también incluye lo bárbaro y lo popular), se vuelve necesaria una reflexión sobre la ontología en sí.

El pensamiento crítico surge de la periferia -a la cual habría que agregarle la periferia social, las clases oprimidas, los lumpen-, pero termina siempre por dirigirse hacia el centro. Es su muerte como filosofía crítica; es su nacimiento como ontología acabada y como ideología. El pensar que se refugia en el centro termina por pensarlo todo como la única realidad. Fuera de sus fronteras está el no-ser, la nada, la barbarie, el sinsentido, las lenguas primitivas, los mundos salvajes. El ser es el fundamento mismo del sistema o la totalidad de sentido de la cultura del mundo del centro ${ }^{41}$.

Para resumirlo en una sola frase: la ontología es y ha sido siempre desde el principio, politica: es ontología política. Aunque parezca una yuxtaposición entre dos palabras en realidad distintas, es importante en este momento que lo veamos como algo compacto. Para repetir otra vez el argumento: como la ontología es una apelación a todo "lo que es" presupone una determinada concepción de la totalidad, y por lo tanto excluye lo otro -en este preciso momento se convierte en política. Y aunque el primer término parezca más "fundamental" y el segundo más "óntico", deberíamos rehuir cualquier tipo de fundacionalismo que, como el árbol de Descartes, vea en la ontología unas profundas raíces que conducen hasta las más altas ramas de la política ${ }^{42}$. Al revés, ambos respectos están imbricados de forma horizontal, no vertical.

Contra la ontología clásica del centro, desde Hegel hasta J. Habermas, por nombrar lo más lúcido de Europa, se levanta un contradiscurso, una Filosofía de la Liberación de la periferia, de los oprimidos, de los excluidos, la sombra que la luz del ser no ha podido iluminar, el silencio interpelante sin palabra todavía. Desde el no-ser, la nada, lo opaco, el otro, la exterioridad, el excluido, el misterio del sinsentido, desde el grito del pobre parte nuestro pensar. Es entonces, una "filosofía bárbara", que intenta sin embargo un proyecto de trans o metamodernidad ${ }^{43}$.

Después de este manifiesto de la Filosofía de la Liberación, de esta declaración de intenciones y toma de partido en toda regla, solo cabe hacer una pregunta: ¿si la ontología es el problema, no sería la meontología la solución? Tal y como concluye Critchley, "el problema identificado por Levinas es el problema correcto. El problema con Levinas yace en su respuesta a este problema"44. Y nosotros añadimos: lo otro de la ontología no es la heterología en sí, sino la meontología. Efectivamente, el principal objetivo de Levinas es "escapar el clima de la filosofía heideggeriana, pero no por

\footnotetext{
E. Dussel, op. cit., p. 21.

42 R. Descartes, Los principios de la filosofía, Barcelona, Alianza, 2002, p. 15

43 E. Dussel, op. cit., pp. 30-1.

44 S, Critchley, op. cit., p. 132.
} 
una filosofía que fuera pre-heideggeriana" ${ }^{" 45}$. Solo cabe apuntar que lo otro del ser es el no-ser, y no lo otro en sí. Más aún, es posible que por una ironía del destino, la metafísica occidental, al privilegiar el ser sobre la nada, se haya hecho un flaco favor a sí misma, frente a la intuición de algunos pueblos llamados "bárbaros". No es ningún secreto que los griegos no conocieron el 0 (fundamental para el álgebra), este fue inventado en la India, y no se introdujo en Europa hasta el s. XIV, gracias a los árabes, no sin gran oposición por parte de la teología cristiana ${ }^{46}$. También es sabido que el concepto fundamental desde el budismo mahayana a la escuela Kyoto es el de Súnyatā (vacío) ${ }^{47}$. Por último, el título de este ensayo justamente apunta a que el pensamiento político latinoamericano reciente, como el de Dussel o Laclau, ha mostrado una mayor preocupación por la ontología negativa. Sin embargo, en este preciso instante es necesaria una importante aclaración: ¿no estaríamos esencializando la ontología política europea en el ser y la filosofía de la liberación de la periferia en el noser? Una curiosa esencialización, sin duda, la de otorgar precisamente una falta de esencia (o vacío), pero no sin riesgos de convertirse en un nuevo esencialismo, al fin y al cabo. Dussel es perfectamente consciente de este problema y quizás por esto añade:

Los filósofos modernos europeos piensan la realidad que les hace frente: desde el centro interpretan la periferia. Pero los filósofos coloniales de la periferia repiten una visión que les es extraña, que no es la propia: se ven desde el centro como no-ser, nada, y enseñan a sus discípulos, que todavía son algo (por cuanto son analfabetos de los alfabetos que se les quiere imponer), que en verdad nada son; que son como nadas ambulantes de la historia. Cuando han terminado sus estudios (como alumnos que todavía eran algo, porque eran incultos de la filosofía europea), terminan como sus maestros coloniales por desaparecer del mapa (geopolíticamente no son, filosóficamente tampoco). Esta triste ideología con el nombre de filosofía es la que todavía es enseñada en la mayoría de los centros filosóficos de la periferia por la mayoría de sus profesores ${ }^{48}$.

Para resumirlo en una sola frase: la periferia puede ser vista como una "nada ambulante de la historia" solo desde la perspectiva del centro. Aquí resulta fundamental desenredar tres movimientos que la ontología política europea ha realizado simultáneamente: 1) es ella la que diferencia, con Parménides, el "camino del ser" del "camino del no-ser"; 2) convierte esta diferencia en una jerarquía en la que solo un lado es tan siquiera "pensable"; y 3) asocia (más o menos conscientemente) el uno con el centro y el otro con la periferia, la barbarie y el pueblo. Estos tres movimientos (diferencia, jerarquía y asociación) se hallan tan imbricados en la práctica que se confunden en un todo único e inapelable. Tal y como describe Dussel,

45 E. Levinas, De l'existence a l'existant, Paris, Vrin, 2004, p. 19.

46 C. Seife, Zero: The Biography of a Dangerous Idea, Nueva York, Penguin, 2000, pp. 69-115.

47 K. Nishitani, Religion and Nothingness, Berkeley, University of California Press, 1983.

48 E. Dussel, op. cit., p. 28. "la cultura africana, asiática, latinoamericana tiene un ámbito propio que no ha sido comprendido ni incluido (porque es despreciado como incultura, barbarie, analfabetismo, hechicería) en el sistema escolar, universitario o de los medios de comunicación. Son interpretados por el sistema cultural vigente, racionalista, pretendidamente universal como nada, no-ser, caos, irracionalidad"49. Una deconstrucción plena de esta maraña construida entre el no-ser y lo otro debería revertir cada uno de los tres momentos mencionados. En este sentido, Derrida no se cansó de repetir que la deconstrucción no es un "método", pero si hay algo parecido a una "estrategia general" en este trabajo es la siguiente, que vale la pena citar in extenso:

Hay que avanzar por lo tanto un gesto doble, según una unidad a la vez sistemática y como apartada de sí misma, una escritura desdoblada, es decir multiplicada por ella misma, que he llamado, en "La doble sesión", una doble ciencia: por una parte, atravesar una fase de inversión. Insisto mucho y sin cesar sobre la necesidad de esta fase de inversión que quizá se ha buscado desacreditar prematuramente. Dar derecho a esta necesidad significa reconocer que, en una oposición filosófica clásica, no tenemos que vérnoslas con la coexistencia pacífica de un vis-a-vis, sino con una jerarquía violenta. Uno de los dos términos se impone al otro (axiológicamente, lógicamente, etc.), se encumbra. Deconstruir la oposición, significa, en un momento dado, invertir la jerarquía. Olvidar esta fase de inversión es olvidar la estructura conflictual y subordinante de la oposición. Significa pasar demasiado aprisa, sin detenerse sobre la oposición anterior, a una neutralización que, prácticamente, dejaría el campo anterior en su estado y se privaría de todo medio de intervenir efectivamente. Se sabe cuales han sido siempre los efectos prácticos (en particular políticos) de los pasajes que saltan inmediatamente por encima de las oposiciones, y de las protestas en la simple forma del ni/ni. [...]

Dicho esto -y por otra parte-, permanecer en esta fase, todavía es operar sobre el terreno y en el interior del sistema deconstruidos. También es necesario, mediante esta escritura doble, justamente, estratificada, cambiada y cambiante, marcar la separación entre la inversión que pone abajo lo que está arriba, deconstruye la genealogía sublimante o idealizante, y la emergencia irruptiva de un nuevo "concepto", concepto de lo que no se deja ya, no se ha dejado nunca, comprender en el régimen anterior. Si esta separación, esta bifaz o esta bifase, ya no puede inscribirse más que en una escritura bífida (y vale en principio para un nuevo concepto de la escritura que a la vez provoca una inversión de la jerarquía palabra/escritura, como de todo su sistema adyacente, y deja detonar una escritura en el interior mismo de la palabra, desorganizando así todo el orden recibido e invadiendo todo el campo), no puede ya marcarse más que en un campo textual que llamaré agrupado: al límite, es imposible de precisar; un texto unilineal, una posición puntual, una operación firmada por un solo autor son por definición incapaces de practicar esta operación ${ }^{50}$.

\footnotetext{
Ibidem, p. 104

50 J. Derrida, Positions, Paris, Minuit, 1972, p. 96.
} 
Así pues, en la primera parte de este ensayo hemos reconocido que el supuesto "olvido del ser" se asienta sobre la exclusión más fundamental y originaria de la nada. Habiendo terminado esta segunda parte creemos haber demostrado suficientemente que en esta "oposición filosófica clásica, no tenemos que vérnoslas con la coexistencia pacífica de un vis-a-vis, sino con una jerarquía violenta". Por lo tanto, acometemos la primera "fase" de la deconstrucción, invirtiendo esta "jerarquía violenta" y preguntamos: asumiendo que lo bárbaro y lo popular se correspondan con el no-ser (que ya hemos visto que no es esencialmente así, sino que representa un movimiento político interesado): ¿qué pasaría con la nada? Sin embargo, esto no es suficiente, pues se sigue moviendo dentro de la oposición binaria de la ontología helenocéntrica. Derrida encontró su "nuevo concepto",

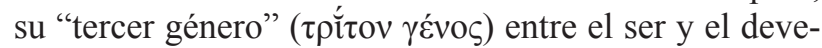
nir, en la $\chi \omega ́ \rho \alpha$ del Timeo de Platón, y nosotros creemos que aquello que puede deconstruir el dualismo entre ser y no-ser en la ontología política europea se puede hallar en un concepto igualmente "vacío", el vacío que Laclau otorga al populismo. Este también puede ser categoriza-

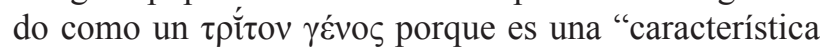
del ser" (de un pueblo), y a la vez no es (carece de esencia). Sin embargo, antes de llegar a esta conclusión tenemos que asegurarnos de haber completado la inversión de la jerarquía de la ontología política europea, y por eso pasamos a fijarnos ahora un momento en su forma más acabada, la de Carl Schmitt.

\section{El horror vacui de la ontología política europea}

¿Para qué sirven las lecciones más hermosas, para qué valen los conceptos más claros, para qué sirve el espíritu? Lo que importa es la esencia. $\mathrm{O}$ el ser, o la existencia.

Carl Schmitt ${ }^{51}$

De acuerdo con Heidegger, la metafísica es onto-teo-logía, esto es: el discurso ( $\lambda$ ó $\gamma \circ \varsigma$ ) de "lo más fundamental" ( $\tau \tilde{\omega}$ ơv), y a la vez de "lo más alto" $(\theta \varepsilon \circ \varsigma)$; simultáneamente "universal" y "suprema" 52 . Aunque parezca una definición un tanto barroca y oscura, se trata simplemente de la traducción y la síntesis de los dos objetos de estudio principales que Wolff concedió a la metafísica: el "ser en tanto que ser" (das Sein als solches) y el "ente en su totalidad" (das Seiende im Ganzen). Ahora bien, si Nietzsche representa la consumación de esta tradición en su inversión final, Schmitt representa su último repunte político. Está claro que el autor de la Teología política encarna como nadie la reactivación de la segunda pata de la metafísica definida como onto-teo-logía: "todos los conceptos centrales de la moderna teoría del Estado son conceptos teológicos secularizados"53. Pero ¿qué pasa con la primera pata, la ontología política? Mi punto es que Schmitt no sólo tiene una concepción de esta, sino que sobre todo representa la forma más acabada de la metafísica como onto-teo-logía política. En efecto, el

\footnotetext{
C. Schmitt, Ex captivitate salus, Madrid, Trotta, 2010, p. 25.

52 M. Heidegger, ¿Qué es metafísica?, Madrid, Alianza, 2009, p. 86.

53 C. Schmitt, Teología política, Madrid, Trotta, 2009, p. 37.
}

"enemigo" político no tiene por qué ser moralmente malo, estéticamente feo o un competidor económico, "simplemente es el otro, el extraño, y para determinar su esencia basta con que sea existencialmente distinto y extraño, $[. .$.$] la negación del propio modo de existencia" { }^{54}$. Nótese aquí el lenguaje cargado de existencialismo que se erige en toda una ontología política: "la destrucción física de la vida humana no tiene justificación posible, a no ser que se produzca, en el estricto plano del ser, como afirmación de la propia forma de existencia contra una negación igualmente óntica de esa forma" ${ }^{\prime 5}$. He aquí una quinta forma de negación (Verneinung) que no habíamos tenido en consideración en la tabla lacaniana del principio: destrucción o, mejor, aniquilación (Vernichtung). En efecto, como no se piensa políticamente la "nada", ni tampoco se tiene una concepción positiva del "vacío", se reduce ambos términos a la "aniquilación" (Vernichtung). O como lo expresa más directamente Dussel: "la guerra es la ontología práctica; es el ser que prácticamente reduce al otro al no-ser. Parménides funda así la estrategia y la táctica de Von Clausewitz y del Pentágono" ${ }^{56}$. A esta última "cadena de equivalencias" le falta Schmitt, porque justamente en su obra podemos encontrar la máxima expresión del horror vacui que recorre la ontología política europea. A propósito del análisis de la concepción marxista de "dictadura" dice:

Desde una perspectiva marxista, del proletariado solo se puede decir que es, de forma absoluta, la negación de la burguesía, o que sería propio de un socialismo no científico el imaginarse el aspecto que tendrá el Estado proletario del futuro. Es una necesidad sistemática que todo lo concerniente al proletariado sólo pueda ser determinado negativamente. Sólo cuando ello se haya olvidado por completo podrán hacerse algunos intentos de definir positivamente al proletariado. Lo único que puede decirse de la sociedad del futuro es que en ella no habrá antagonismos de clase, y del proletariado que es la clase social que no participa en la plusvalía, que no es poseedora de cosas, que no conoce ni familia ni patria, etc. El proletario no es, socialmente, nada. De él cabe decir que, al revés que el burgués, no es nada más que un ser humano ${ }^{57}$.

Para asegurarnos de que no estamos sobre-interpretando el texto, Schmitt insiste en una nota al pie a este mismo pasaje: "ésta no es una mera forma de hablar. Si en una sociedad es posible que haya algo que socialmente no es nada, con ello se demostraría que no persiste ningún orden social. No puede haber ningún orden social que contenga un vacío así" 58 . Lo que Schmitt descubre en la obra de Marx es cierto, pero su valor tiene que

\footnotetext{
C. Schmitt, El concepto de lo político, Madrid, Alianza, 2009, p. 57. Ibidem, p. 78.

56 E. Dussel, op. cit., p. 72. Aún más: “el que se opone al aplanamiento es el otro. Como otro que el sistema está más allá del ser; como el ser es y el no-ser no es, el tal no es. Si habla, si provoca, si irrumpe, es la irrupción o la palabra expresión del no-ser. Decir el no-ser es lo falso. Antes que el otro continúe su tarea de falsificación, de desmoralización del sistema, el héroe se lanza sobre el enemigo, el otro, y lo aniquila, lo mata, lo asesina" (ibidem, p. 68).

57 C. Schmitt, Los fundamentos histórico-espirituales del parlamentarismo en su situación actual, Madrid, Tecnos, 2016, p. 125.
}

58 Ibidem, $13 \mathrm{n}$. 
ser invertido. En efecto, en la Introducción para la crítica de la Filosofía del derecho de Hegel, Marx convoca a una clase que tenga la osadía de presentarse como el "representante negativo de la sociedad" haciendo suyo el lema "yo no soy nada y debería serlo todo" 59 . Esta formulación -"los nada de hoy todo han de ser", que data desde el panfleto del abate Sieyès ¿Qué es el tercer estado? hasta la actual Internacional francesa-, es encumbrada como definición de la clase trabajadora en la frase más conocida del Manifiesto comunista: el proletariado "no tiene nada que perder salvo sus cadenas"60. Existe, pues, una lógica de la nada en Marx (y de la plenitud, que es su corolario), pero esta no es vista como "desorden", como en Schmitt, sino como precondición de la libertad. Dussel, quien estudió a Marx durante décadas, también parece coincidir en este punto: "la «plena nada»-del Manuscrito II de 1844 de Marx-, la del otro, el trabajador no-capital (todavía no-ser del capital), es la posición de la persona como sujeto de trabajo que no ha sido subsumido todavía en la totalidad del capital. Es «nada (Nichts)», tanto para Marx como para nuestra metafísica de la liberación, y sin embargo libre, real" ${ }^{1}$. Recordemos: si ov̉oía (substantia) significa tanto "esencia" como "riqueza", aquellos que no poseen nada, que no participan de la propiedad, tampoco son nada desde el punto de vista de la ontología política tradicional. La cuestión es cómo se concibe esta nada. Como se ha dicho en otra parte, la lectura de Marx por parte de Schmitt nos puede ofrecer (aunque invertida) la línea de demarcación ontológico-formal (no óntico-histórica como se suele encontrar a veces en el imaginario -eurocéntrico-izquierda/derecha) entre un populismo reaccionario y uno progresista: esta "depende de la concepción del «pueblo»: si en el caso del primero se ve como un ser con una determinada esencia, en el caso del segundo, como un vacío" ${ }^{\prime 2}$. Pero para demostrar esta tesis definitivamente necesitaremos pasar a Laclau, pues en Marx la nada del "representante negativo de la sociedad" aún es absoluta (corresponde con el "todo") y económicamente objetiva (creada por las condiciones materiales), no relativa y construida politicamente como encontraremos en el populismo.

\section{El vacío del populismo latinoamericano}

Sin la producción de vacío no hay “pueblo", ni populismo, pero tampoco democracia.

Ernesto Laclau ${ }^{63}$

Para empezar, Laclau no menciona el "vacío" ni nada que se le parezca ni una sola vez en su opera prima,

$59 \quad$ K. Marx, "Introducción para la crítica de la Filosofía del derecho de Hegel”, G.W.F. Hegel, Filosofia del derecho, Buenos Aires, Claridad, 1968, p. 19.

60 K. Marx y F. Engels, Manifiesto comunista, Madrid, Alianza, 2008, p. 86 .

61 E. Dussel, op. cit., p. 60.

62 A. Porta Caballé, "El vacío de Podemos: meontología política del cambio en España", Escrituras americanas, 2020, en publicación.

63 E. Laclau, On Populist Reason, Londres, Verso, 2007, p. 169.
Política e ideología en la teoría marxista (1977). De lo que podemos extraer que su preocupación por este concepto sólo se dará en su etapa como post-marxista, no cuando aun permanezca dentro de los márgenes de esta tradición, con el "reduccionismo de clase" como único enemigo. Pero incluso en su clásico con Chantal Mouffe, Hegemonía y estrategia socialista (1985), ya más imbuido de teoría (post-)estructuralista, el "vacío" tan solo aparece de una determinada forma, si bien demasiado teorética. En efecto, se habla de un "doble vacío" en el discurso esencialista de la II Internacional que el concepto de "hegemonía" tendría que venir a llenar ${ }^{65}$. Ese era fruto de un dualismo determinado/indeterminado que no podía dar cuenta ni de la "primacía de lo político" ni de la "unidad de clase" en pensadores como Luxemburg, Kautsky o Sorel. Sin embargo, no sería hasta Nuevas reflexiones sobre la revolución de nuestro tiempo (1990) -que es sin duda su libro más eminentemente filosófico- donde el "vacío" despuntaría en su significación final. Se trata del primer intento de analizar directamente a Marx, y entrar al corazón de los principales problemas: agencia/estructura, contingencia/determinación, dislocación/inmanencia y, por supuesto, particularidad/universalidad. Es en este último debate donde entra el "vacío", en dos sentidos: como una "tendencia" de la universalidad, y como la "plenitud ausente" de la sociedad. En una proto-definición del populismo, a propósito del milenarismo, Laclau dice:

La plenitud de la comunidad deviene una forma vacía y su relación con las demandas concretas de los diferentes grupos se convierte por tanto en inestable y hegemónica. Podemos ver, entonces, el nuevo tipo de relación entre "particularidad" y "universalidad" que este tipo de vaciamiento implica ${ }^{66}$.

Uno de los aspectos más interesantes del concepto de "vacío" de Laclau es que este sustantivo siempre se verbaliza: o bien se trata de un significante "tendencialmente vacío" (y por lo tanto representa una nada relati$v a$, no absoluta como la de la metafísica: nihil privativum y no nihil negativum) o bien se da un vacia-miento

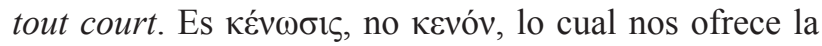
puerta de entrada a la teología negativa de Laclau que trataremos al final. Pero no avancemos acontecimientos, de momento tenemos que el descubrimiento del proceso de "vaciamiento" como tendencia propia de la universalidad prepara el terreno para el texto culminante en este sentido: “¿Por qué los significantes vacíos importan para la política?" en Emancipación(es) (1996). “Un significante vacío es, estrictamente hablando, un significante sin significado", reza la primera frase del artículo, y lo que sigue es un argumento derridiano sobre cómo la condición de posibilidad de un sistema de significación -su límite- representa también lo que constituye su

\footnotetext{
E. Laclau, Politics and Ideology in Marxist Theory: Capitalism, Fascism, Populism, Londres, Verso, 2011, p. 10.

65 E. Laclau y C. Mouffe, Hegemony and Socialist Strategy: Towards a Radical Democratic Politics, Londres, Verso, 2014, pp. 37-8.

66 E. Laclau, New Reflections on the Revolution of Our Time, Londres, Verso, 1990, p. 80.
} 
condición de $i m$-posibilidad ${ }^{67}$. Este sugerente texto no consta ni de una sola nota a pie de página, y esto contribuye a que sea leído prima facie como un argumento estrictamente post-estructuralista. Sin embargo, una lectura atenta descubre el sustantivo "ser", alguna vez incluso en mayúsculas, en clara referencia a Heidegger.

Lo que es excluido del sistema, lejos de ser algo positivo, es el simple principio de positividad - puro ser. [...]

Sólo si los significantes se vacían de su adhesión a significados particulares y asumen el rol de representar el puro ser del sistema -o, mejor, el sistema como puro Ser- que esta significación es posible. ¿Cuál es el fundamento ontológico de esta inversión, qué lo hace posible? [...]

El ser o la sistematicidad del sistema que es representada por los significantes vacíos no es un ser que no se haya actualizado en realidad, sino uno que es constitutivamente inalcanzable ${ }^{68}$.

El “puro Ser” aquí es utilizado como sinónimo de la "sistematicidad del sistema", y por lo tanto convive un argumento estructural con uno ontológico. El vacío aquí es un "efecto", un "producto" de la equivalencia del ser que borra toda diferencia. ¿Cómo puede ser que algo como un "vacío" surja del ser? Recordemos que es una máxima para la metafísica antigua ex nihilo nihil fit. Pero el argumento aquí es heideggeriano en un sentido profundo, pues ya dijimos que para Heidegger "la nada es una característica del ser"69 _"son" lo mismo. Sin embargo, no se encuentra de acuerdo con la letra pequeña de Heidegger, ya que este consideraba también el "vacío" actual de la palabra ser como el resultado de una decadencia lingüística, gramática y etimológica, que ha borrado y mezclado sus tres significaciones radicales ${ }^{70}$. “¿Es a causa del ser que sea tan confuso, depende de la palabra que permanezca tan vacía o de nosotros que, pese a nuestros esfuerzos y nuestro acoso del ente, no obstante hemos caído fuera del ser?" este segundo camino, pero nosotros querríamos explorar el primero: la condición de posibilidad del ser -su "universalidad"- es justamente su condición de im-posibilidad-su "vacío". O para ponerlo en términos lacanianos, la falta de significante se convierte en el significante de la falta.

Todo esto que puede parecer "abstracto" tiene para Laclau, como para nosotros aquí, una intencionalidad y un objetivo fundamentalmente políticos. Laclau intenta deconstruir la metafísica de la presencia para dar cuenta de un fenómeno, el populismo en general, y el peronismo en particular, que no acaba de encajar dentro de la ontología política tradicional. En otro artículo de Emancipación(es), Laclau liga explícitamente la cuestión del "vacío" con la experiencia autobiográfica que pretende explicar. Ese es encumbrado como el único que puede dar cuenta tanto del auge como del declive de Perón: su exilio en Madrid lo convierte en el can-

E. Laclau, Emancipation(s), Londres, Verso, 1996, pp. 36, 37.

Ibidem, pp. 38, 39.

69 M. Heidegger, Seminario de Le Thor 1969, Córdoba, Alción, 1995, jueves 11 de septiembre.

70 M. Heidegger, Introducción a la metafísica, op. cit., pp. 55-73.

71 Ibidem, p. 42. didato "ideal" para representar el significante vacío de la cadena equivalencial de demandas insatisfechas bajo la dictadura, pero semejante "lógica salvaje" está fuera de todo control, incluso del propio Perón, cuando gana las elecciones de 1973, y debe encarnarlo en "políticas concretas"72. Vale la pena añadir que, con este movimiento teórico, la lógica del "no-ser de la periferia" que hemos criticado con Dussel queda absolutamente invertida. Laclau hace de la necesidad virtud, y convierte la supuesta "nada ambulante de Latinoamérica" de la mirada eurocéntrica en un vacio positivo y productivo que tiene algo que decir y aportar a la ontología política. Pensar lo impensado de la ontología política europea significa pensar el vacío. Quizás, y especialmente ahora, no es Latinoamérica, con su "desarrollo desigual y combinado" y sus formas políticas "bárbaras" o "populares" la que no encaja en el imaginario izquierda/derecha, sino Europa que, con sus prejuicios plenistas helenocéntricos, no entiende el vacío del populismo.

Quizás también esto es lo que subyace detrás de la violenta polémica entre Laclau y Zizek en Contingencia, Hegemonía, Universalidad (2000), en la cual este regresa a una concepción de la lucha de clases marxista más ortodoxa que, por ejemplo, en El sujeto espinoso, publicado tan solo un año antes ${ }^{73}$. Curiosamente, esta regresión se da frente a un Laclau que representa la máxima expresión del tema que nos ocupa: "el universal es un lugar vacío (empty), un vacío (void) que solo puede ser llenado por el particular, pero el cual, gracias a su propio vacío produce una serie de efectos cruciales en la estructuración/destructuración de las relaciones sociales"74. Laclau desarrolla esta concepción del universal con el principal objetivo de abrir un espacio para lo político (y la democracia): sólo si los significantes comunes de la sociedad están "tendencialmente vacíos" de contenido concreto se abre el terreno para la lucha hegemónica entre distintas fuerzas políticas particulares. En una sola frase, el universal es un campo de batalla. Sin embargo, y como previene el propio Laclau, tenemos que ir con cuidado a la hora de no volver a congelar y reificar estas dos categorías particular/universal en una metafísica dualista. No es el caso de que haya, "por un lado", el universal vacío, y "por el otro lado", las fuerzas políticas particulares, sino que se da un proceso de "contaminación mutua" en el cual la mediación es la hegemonía ${ }^{75}$. Contra Marx, tampoco hay una nada o plenitud absolutas encarnadas por un "representante negativo de la sociedad" (el proletariado) que sería garante de la libertad universal del "nada que perder". Aquello que la expresión "tendencialemente vacío" pretende poner de relieve es que esta "nada" es relativa y construida políticamente.

Una sola pregunta recorre toda esta discusión: ¿cuál es entonces la diferencia con la definición de la

E. Laclau, Emancipation(s), p. 55.

73 S. Zizek, The Ticklish Subject: The Absent Centre of Political Ontology, Londres, Verso, 1999, pp. 100-101.

74 E. Laclau, "Identity and Hegemony: The Role of Universality in the Constitution of Political Logics", J. Butler, E. Laclau y S. Zizek, Contingency, Hegemony, Universality. Contemporary Dialogues On the Left, Londres, Verso, 2000, p. 58.

75 Ibidem, pp. 69-70. 
democracia como "el lugar vacío del poder" avanzada ya por Lefort ${ }^{76}$ ? Es evidente que este estaba haciendo una comparación óntico-histórica con la lógica de la "encarnación" hallada en la monarquía absolutista, mientras que Laclau está haciendo un argumento ontológico-formal sobre lo político. Sin embargo, esta pregunta también debiera preocuparle a él, puesto que La razón populista (2005) se puede leer como una clara demarcación con la teoría de Lefort sobre la base del sujeto. En efecto, lo que aporta esta última etapa de Laclau y que se encontraba más o menos ausente en las previas (crítica al reduccionismo de clase, deconstrucción del marxismo, hegemonía y universalidad) es el descubrimiento de un sujeto que lleve a cabo justamente el vaciamiento. Este se encuentra en la "identidad popular", la cual "funciona como un significante tendencialmente vacío"77.

La dificultad con el análisis de la democracia de Lefort es que se concentra exclusivamente en régimenes liberaldemocráticos, y no presta suficiente atención a la construcción de sujetos populares-democráticos. Esto tiene una serie de consecuencias que limitan el alcance del análisis. Para poner un ejemplo: para Lefort, el lugar del poder en democracia está vacío. Para mí, el vacío es un tipo de identidad, no un lugar estructural ${ }^{78}$.

La gran novedad y originalidad de Laclau sobre la cuestión del vacío se encuentra en estas líneas. El vacío deja de ser un locus socialmente objetivo (constituido por las condiciones materiales, como en Marx) para pasar a representar la construcción de un sujeto, o más bien de su falta. Si cuando el vacío apuntaba a la constitución del universal hacía referencia a su falta de fundamento, cuando es aplicado a la construcción de un "pueblo" denota más bien su falta de esencia. Dos conclusiones se derivan de este movimiento final. En primer lugar, La razón populista puede y debe ser leída en gran medida como un trabajo de inversión y deconstrucción de la mirada eurocéntrica hacia el populismo y Latinoamérica. En el primer capítulo enumera los distintos prejuicios que forman parte del "desdén elitista" hacia el populismo latinoamericano: su "simplicidad", "ambivalencia", "ambigüedad"... en una palabra, su "vacío". Estos términos, que además son lanzados como armas arrojadizas, no solo no son negados, sino que son apropiados como características del populismo, su valor es invertido y se erigen como momentos de una nueva lógica política. "El relativo vacío y simplicidad del populismo, que en la mayoría de los casos es el preludio de su desdén elitista, no debe ser aproximado en términos de lo que estos procesos de simplificación y vaciamiento intentan conseguir -esto es, la racionalidad social que intentan expresar"79. En este sentido, Laclau sigue el "doble gesto" derridiano que hemos citado antes. "El carácter vacío de los significantes que dan unidad o coherencia al campo popular no

\footnotetext{
${ }_{76}$ C. Lefort, Essais sur le politique XIXe-XXe siècles, Paris, Seuil, 1986, p. 42.

77 E. Laclau, On Populist Reason, op. cit., p. 96.

78 Ibidem, p. 166.

79 Ibidem, p. 14.
}

es resultado de ningún subdesarrollo ideológico o político", sino de la heterogeneidad social ${ }^{80}$.

La segunda y última conclusión que podemos extraer del giro construccionista en la concepción del vacío acometida por Laclau tiene que ver con la ética y la teología negativa. Critchley preguntaría después si existía un "déficit normativo" en la teoría ontológico-formal de Laclau ${ }^{81}$, pero él ya había respondido avant la lettre en un artículo publicado póstumamente en Los fundamentos retóricos de la sociedad (2014). A primera vista puede parecer sorprendente que Laclau en "Sobre los nombres de Dios" busque refugio en la via negativa de la mística medieval, donde incluso propone una lectura de Dios como "significante vacío" 82 . Pero esta primera sorpresa deja de ser tal si recordamos que Laclau tiene en

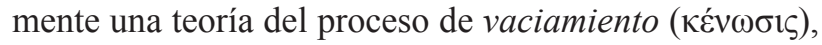

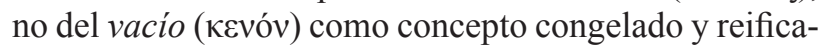
do de la metafísica. Y en el primer término se halla una vinculación con la ética y la teología negativa, pues también se dice de Cristo en la Biblia que "a pesar de tener la forma de Dios, no repuntó como botín (codiciable) el ser igual a Dios, antes se anonadó tomando la forma de siervo, haciéndose semejante a los hombres" (Filipenses 2.6-7). Esta es la lectura subterránea a la que se agarra la mística desde Juan Escoto Erígena hasta Simone Weil y que, como señala Critchley: "no es el proceso de entrar en la plena presencia de Dios, la unio mystica, sino más bien una experiencia de ausencia y nada" $"$. La intención de traer este término teológico secularizado a colación es que el "anonadamiento" (kenosis) puede representar el único concepto que ejerza de contrapeso, ético y necesario, a la Vernichtung de la ontología política. Es mi última tesis en este artículo que el despojamiento de sí, y no la aniquilación del otro, puede representar un ethos alternativo al horror vacui de la ontología política plenista. Por última vez encontramos una curiosa convergencia entre Dussel y Laclau, no solo en la vinculación de la mística con el socialismo, sino sobre todo en la comprensión del no-ser como precondición de la libertad.

Esto nos explica que un Juan de la Cruz diga en su obra lírica El Monte Carmelo que "después de todo hay nada"; o que Babeuf, el primer socialista en plena revolución francesa, escriba a su esposa, en 1794, que se interna en la "noche de la nada". La nada del sistema, el más allá de todo ente, lo que trasciende la totalidad, lo meta-físico ("ante lo cual es necesario guardar silencio", diría L. Wittgenstein), es el no-ser, el otro que lo ha dado. Abrirse a la nada, nihilismo radical, es exponerse por la Libertad que el sistema no condiciona ${ }^{84}$.

Si la "historia de la metafísica" como serie de sentidos del ser del ente en su totalidad toca a su fin, tal y como pronostica Heidegger, quizás no ha llegado el momento

\footnotetext{
Ibidem, p. 98.

81 S. Critchley, "Is there a normative deficit in the theory of hegemony?", S. Critchley, y O. Merchant (eds.), Laclau: A Critical Reader, Nueva York, Routledge, 2006, pp. 113-122.

82 E. Laclau, "On the Names of God", The Rhetorical Foundations of Society, Londres, Verso, 2014, p. 44.

83 S. Critchley, The Problem with Levinas, op. cit., p. 127.

${ }_{84}$ E. Dussel, op. cit., p. 111
} 
de "otro comienzo", sino que justamente la historia de la nada acaba de empezar. En su magnífica Historia de la nada, Sergio Givone liga la primera intrínsecamente al principio de necesidad -vía la "razón suficiente" de Leibniz- mientras que la segunda apuntaría a una nueva noción de libertad ${ }^{85}$. Sin llegar a tal punto, este artículo ha pretendido empezar a transitar este camino, dando tres pasos a la vez necesarios e insuficientes. En primer lugar, hemos conceptualizado mediante la tabla de negaciones de Lacan, que en efecto existe una renegación (Verleugnung) del no-ser en la historia de la metafísica empezando por Parménides, aun más fundamental y originaria que el "olvido del ser" de tipo heideggeriano. En segundo lugar, hemos leído en la reflexión de Dussel sobre Latinoamérica como "nada ambulante" y la categorización por parte de Laclau del populismo como un significante "vacío", dos intentos de salirse de esta misma metafísica helenocéntrica. Juntando ontología y política hemos reconocido que esa renegación del no-ser no tiene nada de "neutral", sino que se ha asociado con el repudio de lo bárbaro, lo popular y lo femenino. Mediante un breve ex cursus sobre Schmitt y Marx, hemos podido comprobar cómo, en el primer caso, se trata realmente de una re-negación de la nada porque el menosprecio político a esta idea se reconceptualiza ontológicamente como “aniquilación” (Vernichtung). Del lado de Marx, si bien se trata indudablemente del pionero del concepto de "vacío social" como "representante negativo de la sociedad", este es aun absoluto (por inspiración hegeliana) y objetivo (determinado por el modo de producción económico) y habrá que esperar a Laclau para encontrar su reformulación relativa y politicamente construida. Por último, hemos propuesto que bajo la caracterización del populismo como un significante "vacío" trabaja en Laclau una idea de kenosis que no solo puede plantear una alternativa ontológica y política a la aniquilación del otro, sino también ética. Decíamos que estos tres pasos y medio son necesarios, pero no suficientes, porque una investigación de mayor envergadura debería conducir a la comparación de la idea de "vacío" en Laclau no solo con la de Lefort sino también con el resto de teóricos políticos posfundacionales ${ }^{86}$.
85 S. Givone, Historia de la nada, Buenos Aires, Adriana Hidalgo editora, 2009, pp. 16-19.
86 En este sentido, la excelente exposición de Antonio Gómez Villar (Ernesto Laclau y Chantal Mouffe: populismo y hegemonía, Barcelona, Gedisa, 2018) ya ha avanzado una comparación con Rancière sobre la idea de "vacío" (pp. 106-110). 


\section{Bibliografía}

Aristóteles, Física, Madrid, Gredos, 1995.

-, Metafísica, Madrid, Alianza, 2008.

Ayer, A. J. (ed.), Logical Positivism, Nueva York, The Free Press, 1959.

Bass, A., Difference and Disavowal: The Trauma of Eros, Stanford, Stanford University Press, 2000.

-, Fetishism, Psychoanalysis and Philosophy: the Iridescent Thing, Nueva York, Routledge, 2018.

-, "Fetishism, Reality, and «The Snow Man»", American Imago, 48(3).

Butler, J., Bodies That Matter, Nueva York, Routledge, 2011.

-, Gender Trouble, Nueva York, Routledge, 2006.

Bernabé, A. (ed.), Fragmentos presocráticos: de Tales a Demócrito, Madrid, Alianza, 2008.

Close, F., The Void, Oxford, Oxford University Press, 2008.

Critchley, S., The Problem with Levinas, Oxford, Oxford University Press, 2015.

-, y Merchant, O. (eds.), Laclau: A Critical Reader, Nueva York, Routledge, 2006.

Derrida, J., Positions, Paris, Minuit, 1972.

Descartes, R., Los principios de la filosofia, Barcelona, Alianza, 2002.

Dussel, E., Filosofía de la Liberación, México, Fondo de Cultura Económica, 2018.

Fink, B., A Clinical Introduction to Lacanian Psychoanalysis: Theory and Technique, Cambridge, Harvard University Press, 1997.

Freud, S., Obras completas (Vol. II): Estudios sobre la histeria, Buenos Aires, Amorrortu, 2000.

-, Obras completas (Vol. IV): La interpretación de los sueños (primera parte), Buenos Aires, Amorrortu, 1991.

-, Obras completas (Vol. V): La interpretación de los sueños (segunda parte), Buenos Aires, Amorrortu, 1991.

-, Obras completas (Vol. VII): Tres ensayos de teoría sexual y otras obras, Buenos Aires, Amorrortu, 1992.

-, Obras completas (Vol. XIX): El yo y el ello y otras obras, Buenos Aires, Amorrortu, 2000.

Givone, S., Historia de la nada, Buenos Aires, Adriana Hidalgo, 1995.

Gómez Villar, A., Ernesto Laclau y Chantal Mouffe: Hegemonía y populismo, Barcelona, Gedisa, 2018.

Hegel, G. W. F., Ciencia de la lógica (Vol. I): Ciencia objetiva, Madrid, Abada, 2011.

-, Filosofía del derecho, Buenos Aires, Claridad, 1968.

Heidegger, M., Carta sobre el humanismo, Madrid, Alianza, 2006.

-, ¿Qué es metafisica?, Madrid, Alianza, 2009.

-, Introducción a la metafísica, Barcelona, Gedisa, 2003.

-, Four Seminars, Bloomington, Indiana University Press, 2003.

Irigaray, L., “Ce sexe qui n'est pas un”, Les Cahiers du GRIF, 5, 1975.

-, Éthique de la différence sexuelle, Paris, Minuit, 1984.

-, Speculum de l'autre femme, Paris, Minuit, 1974.

Kristeva, J., Polylogue Paris, Seuil, 1977.

Lacan, J., Le Séminaire (Vol. III): Les psychoses Paris, Seuil, 2018.

Laclau, E., Emancipation(s), Londres, Verso, 2007.

-, New Reflections on the Revolution of Our Time, Londres, Verso, 1990.

-, Politics and Ideology in Marxist Theory: Capitalism, Fascism, Populism, Londres, Verso, 2011.

-, On Populist Reason, Londres, Verso, 2007.

-, The Rhetorical Foundations of Society, Londres, Verso, 2014.

-, (ed.), The Making of Political Identities, Londres, Verso, 1994.

-, y Mouffe, Ch., Hegemony and Socialist Strategy: Towards a Radical Democratic Politics, Londres, Verso, 2014.

-, Butler, J. y Zizek, S., Contingency, Hegemony, Universality, Londres, Verso, 2000.

Lefort, C., Essais sur le politique XIXe-XXe siècles, Paris, Seuil, 1986.

Levinas, E., Autrement qu'être, ou au-delà de l'essence, Paris, Livre de Poche, 2004.

-, De l'existence a l'existant, Paris, Librairie Philosophique J. Vrin, 2004.

Marx, K. y Engels, F., Manifiesto comunista, Madrid, Alianza, 2008.

Nishitani, K., Religion and Nothingness, Los Angeles, University of California Press, 1983.

Pabón, J. M., Diccionario manual griego. Griego clásico-español, Madrid, Vox, 2007.

Platón, Diálogos V: Parménides, Teeteto, Sofista, Político, Madrid, Gredos, 1988.

Porta Caballé, A., "El vacío de Podemos: meontología política del cambio en España". Escrituras americanas, 2020, en publicación.

Ribas, A., Biografia del vacio, Barcelona, Sunya, 2008.

Schmitt, C., El concepto de lo político, Madrid, Alianza, 2009.

-, Ex Captivitate Salus, Madrid, Trotta, 2010.

-, Los fundamentos histórico-espirituales del parlamentarismo, Madrid, Tecnos, 2016.

-, Teología política, Madrid, Trotta, 2009.

Seife, Ch., Zero: The Biography of a Dangerous Idea, Nueva York, Penguin, 2000.

Zizek, S., The Ticklish Subject: The Absent Centre of Political Ontology, Londres, Verso, 1999. 